\title{
Effects of Citric Acid and L-Carnitine on Physical Fatigue
}

\author{
Tomohiro Sugino $^{1}$, Sayaka Aoyagi ${ }^{1,3}$, Tomoko Shirai ${ }^{2}$, Yoshitaka, Kajimoto ${ }^{1,2}$, \\ and Osami Kajimoto ${ }^{2,3, *}$ \\ ${ }^{1}$ Research and Development Division, Soiken Inc. 1-4-2 Shinsenrihigashimachi, Toyonaka, Osaka 560-0082, Japan \\ ${ }^{2}$ Soiken Holdings Inc. 1-4-2 Shinsenrihigashimachi, Toyonaka, Osaka 560-0082, Japan \\ ${ }^{3}$ Department of Biomarker and Molecular Biophysics, Osaka City University Graduate School of Medicine, 1-4-3 \\ Asahimachi, Abeno-ku, Osaka 545-8585, Japan
}

Received 4 June, 2007; Accepted 15 June, 2007

\begin{abstract}
Summary We examined the effects of citric acid and L-carnitine administration on physical fatigue. In a double-blind, placebo-controlled, 3-way crossover study, 18 healthy volunteers were randomized to oral citric acid $(2,700 \mathrm{mg} / \mathrm{day})$, L-carnitine $(1,000 \mathrm{mg} / \mathrm{day})$, or placebo for 8 days. The fatigue-inducing physical task consisted of workload trials on a cycle ergometer at fixed workloads for 2 h on 2 occasions. Before the physical load, salivary chromogranin A, measured as a physiological stress marker, was lower in the group given citric acid than in the group given placebo. Also, after the physical load, the subjective feeling of fatigue assessed with a visual analogue scale was lower in the citric acid group than in the placebo group. In contrast, L-carnitine had no effect on chromogranin A or subjective fatigue. These results suggest that citric acid reduces physiological stress and attenuates physical fatigue, whereas L-carnitine does not.
\end{abstract}

Key Words: physical fatigue, citric acid, L-carnitine, chromogranin A, cycle ergometer

\section{Introduction}

Fatigue is a common symptom both in sickness and in health [1-3]. Chronic or accumulated fatigue can affect an individual's performance. In addition, long-term accumulated fatigue can lead to Karoshi (death as a result of overwork). Recently, there has been a great increase in the use of over-thecounter supplements and naturally occurring nutraceuticals for the attenuation of fatigue [4]. However, there are no established treatment recommendations for fatigue. One reason for this has been the lack of standardized fatigue-inducing tasks or appropriate methods for objective quantification of fatigue.

Fatigue is best defined as difficulty in initiating or sustaining voluntary activities [5]. It can be subdivided into physical

\footnotetext{
*To whom correspondence should be addressed.

Tel: +81-6-6871-8888 Fax: +81-6-6871-8899

E-mail: kajimoto@soiken.com
}

and mental fatigue. Recently, we succeeded in developing physical and mental fatigue-inducing tests and in developing some methods for evaluating physical and mental fatigue by several biomarkers. By using those, we sought to evaluate the effects of two candidate anti-fatigue substances on physical fatigue.

Muscular exercise causes rapid adenosine triphosphate (ATP) consumption, and energy deficiency is an important factor in fatigue [6]. Thus, exogenous dietary substances that can lead to ATP production are considered to be candidate anti-physical fatigue materials.

Citric acid is a key player in the tricarboxylic acid (TCA) cycle [7], which is part of a metabolic pathway involved in the chemical conversion of carbohydrates, fats, and proteins into carbon dioxide and water to generate energy. TCA cycle intermediates decrease in fatigue during prolonged exercise [8]. Indeed, citric acid administration is expected to activate the TCA cycle and also the subsequent oxidative phosphorylation in mitochondria and thereby increase the production of ATP. 
This may reduce physical fatigue if energy deficiency is a cause of fatigue. Before hydroxycitric acid (HCA) was a promising anti-fatigue substance by inhibiting ATP citrate lyase with citric acid [9], but recently it was reported Garcinia cambogia containing HCA had reproductive toxicity [10, 11], so citric acid is superior to $\mathrm{HCA}$ as an anti-fatigue substance in the respect of toxicity.

On the other hand, L-carnitine transports long-chain fatty acids across the inner mitochondrial membranes in the mitochondria, where they are processed by beta-oxidation to produce biological energy in the form of ATP [12]. It has been reported that the serum L-carnitine level is low in some chronic fatigue patients, and L-carnitine administration is used to treat some patients with chronic fatigue syndrome $[13,14]$.

The aim of this study was to investigate the effects of two candidate anti-fatigue substances involved in fuel metabolism, citric acid and $\mathrm{L}$-carnitine, on physical fatigue, using recently developed physical fatigue-inducing tasks and physical fatigue evaluation methods.

\section{Materials and Methods}

\section{Subjects}

Eighteen healthy volunteers, whose background is summarized in Table 1, were enrolled in this double-blind, randomized, placebo-controlled, 3-way crossover trial. The participants were recruited using an advertisement. Current smokers, subjects with a history of medical illness, subjects taking chronic medication or supplemental vitamins, subjects with a body weight less than $40 \mathrm{~kg}$, and subjects who had donated blood within one month before the study or had a blood hemoglobin level less than $12.0 \mathrm{~g} / \mathrm{dl}$ were excluded. The participants' health status was assessed through physical examination and laboratory examinations, including an electrocardiogram, chest X-ray, blood chemistry panel (glucose, hemoglobin A1c, creatinine, blood urea nitrogen, sodium, potassium, chloride, uric acid, asparate aminotransferase, alanine aminotransferase, gamma-glutamyl transpeptidase, and creatine phosphokinase), lipid profile (total cholesterol and triglyceride), complete blood count, and urinalysis. The protocol was approved by the Ethics Committee of Soiken Inc. and Soiken Clinic; all subjects gave their written informed consent.

Table 1. Subject Background

\begin{tabular}{ll} 
No. Subjects & $18(9$ men, 9 women $)$ \\
Age $($ years $)$ & $36.1 \pm 9.9$ (between 21 and 57$)$ \\
Height $(\mathrm{cm})$ & $165.1 \pm 7.7$ \\
Body weight $(\mathrm{kg})$ & $61.4 \pm 7.8$ \\
BMI $\left(\mathrm{kg} / \mathrm{m}^{2}\right)$ & $22.5 \pm 2.6$ \\
\hline
\end{tabular}

\section{Experimental design}

After enrollment, the subjects were randomized into 3 groups to receive the following treatments twice a day for one week before the experimental day in a double-blind fashion: 5 capsules of citric acid [270 mg of citric acid (Fuso Chemical Co., Ltd., Osaka, Japan) and $100 \mathrm{mg}$ of crystalline cellulose (JRS Pharma GmbH \& Co. KG, Rosenberg, Germany)], L-carnitine [146.2 $\mathrm{mg}$ of L-carnitine tartrate (100 mg as free L-carnitine) (Nissin Pharma Inc., Tokyo, Japan) and $153.8 \mathrm{mg}$ crystalline cellulose]; or placebo [230 mg of crystalline cellulose]. The doses of citric acid and L-carnitine were based on previous human studies [1315]. The day before each test day, subjects finished dinner by 8:00 p.m. and then fasted overnight. The subjects were not allowed to bathe. The next morning at 7:15 a.m., the subjects were asked to subjectively rate their fatigue level; blood pressure and heart rate were measured; and blood samples were collected. Thereafter, the subjects had breakfast $[75 \mathrm{~g}$ glucose solution (TRELAN-G 75, Shimizu Pharma, Shizuoka, Japan)] and 5 capsules of placebo, citric acid, or L-carnitine. The fatigue-inducing physical task consisted of workload trials on a cycle ergometer (Aerobike 75XL2 ME; Combi Wellness Co., Tokyo, Japan) at fixed workloads to reach $80 \%$ of the heart rate at the anaerobic threshold for $2 \mathrm{~h}$, as described previously [16]. This task was repeated twice in each (placebo-, citric acid-, or L-carnitine) arm of the study. The physical test began at 8:10 a.m.; blood pressure was measured every $30 \mathrm{~min}$. Just after the end of the first task section at 10:10 a.m., subjects were asked to subjectively rate their fatigue. After the end of the last task section at 0:25 p.m., subjects were again asked to subjectively rate their fatigue; blood pressure and heart rate were measured, and blood samples were collected. At 1:30 p.m., the subjects had lunch. After lunch, to recover from fatigue, the subjects read books or magazines, listened to music, or talked until 4:30 p.m. After the end of the recovery period, the subjects were again asked to subjectively rate their fatigue; blood pressure and heart rate were measured, and blood samples were collected. During the experiment, the subjects could only take water and the specified meals. All participants had the same dinner before the test day and the same lunch on the test day. The tests were conducted in a quiet, temperature- and humidity-controlled environment. For 1 week before each test, subjects refrained from strenuous physical activity and followed their normal diets, as well as their normal drinking and sleeping patterns. The time interval between each test was set at 4 weeks to take into account the female subjects' menstrual cycles.

\section{Visual analogue scale}

The subjects were asked to subjectively rate their fatigue level on a visual analogue scale (VAS) from 0 (no fatigue) to 100 (total exhaustion) before, during, and after physical 
exertion and after the recovery period. The VAS was originally developed for measuring pain level [17] and has been used for fatigue level [18].

\section{Physical performance test}

During the physical performance test, the subjects were asked to perform $10 \mathrm{~s}$ maximum speed trial using a cycle ergometer at $30 \mathrm{~min}(30-\mathrm{min}$ trial) after the start and $30 \mathrm{~min}$ before the end of the test (210-min trial). The torque of each subject was calculated as $8.5 \%$ of the body weight for male subjects and $7.5 \%$ of the body weight for female subjects.

\section{Blood sample analyses}

Blood samples were collected from the brachial vein. To assess serum total protein (TP), blood urea nitrogen (BUN), creatine phosphokinase (CPK), aspartate aminotransferase (AST), lactate dehydrogenase (LDH), triglyceride (TG), free fatty acids, ketone bodies (acetoacetic acid, 3-hydroxybutyric acid), cortisol, citric acid, L-carnitine, and acyl-carnitine, the blood samples were centrifuged at $1,700 \mathrm{~g}$ for $10 \mathrm{~min}$ at $4{ }^{\circ} \mathrm{C}$. The blood samples used to determine the plasma glucose levels were collected in a fluorosodium-containing tube and centrifuged at $1,700 \mathrm{~g}$ for $10 \mathrm{~min}$ at $4^{\circ} \mathrm{C}$. The blood samples used to determine plasma adrenocorticotropic hormone (ACTH) were collected in an ethylenediamine- $N, N, N^{\prime}, N^{\prime}$ tetraacetic acid, disodium salt-containing tube and kept on ice until centrifuged at $1,700 \mathrm{~g}$ for $10 \mathrm{~min}$ at $4^{\circ} \mathrm{C}$. The blood samples used to determine blood lactate were collected in a $0.8 \mathrm{~N}$ perchloric acid-containing tube and kept on ice until centrifuged at $1,700 \mathrm{~g}$ for $5 \mathrm{~min}$ at $4^{\circ} \mathrm{C}$. All of the supernatants were stored at $-80^{\circ} \mathrm{C}$ until analyzed. Assays of serum cortisol and plasma ACTH assays were performed by radioimmunoassay at Special Reference Laboratories (SRL; Tokyo, Japan), and serum CPK, AST, LDH, free fatty acids, citric acid, plasma glucose and blood lactate levels measured by general procedure, L-carnitine and acyl-carnitine levels by enzymatic cycling method at Sakai Bio-clinical Laboratory, Inc. (Osaka, Japan).

\section{Saliva sample analyses}

Saliva samples were collected using Salivett (Sarstedt Akiengesellscaft \& Co.). To access salivary chromogranin A and total protein, the saliva samples were centrifuged at $1,700 \mathrm{~g}$ for $10 \mathrm{~min}$ at $4^{\circ} \mathrm{C}$. All of the samples were stored at $-30^{\circ} \mathrm{C}$ until analyzed. Assay of chromogranin A was performed by enzyme-linked immunosorbent assay at Yanaihara Institute Inc. (Shizuoka, Japan); the total protein assay was performed by Bradford method at Soiken Inc. (Osaka, Japan).

\section{Statistical analyses}

The values are shown as mean $\pm \mathrm{SD}$. Paired $t$ tests with the Bonferroni correction were used to evaluate the significance of differences between the placebo and citric acid groups, and between the placebo and L-carnitine groups. All $p$ values were 2-tailed; $p$ values less than 0.05 were considered to be statistically significant.

\section{Results}

Subjective feelings and physiological and biochemical parameters after citric acid and L-carnitine administration are summarized in Table 2. The VAS score for fatigue in the citric acid group was lower than in the placebo group at the end of the physical load. The score in the placebo group was 74.6 , so the task of $4 \mathrm{hr}$ Physical load could induce over $70 \%$ of full exhaustion in daily life. Mean body weight, systolic blood pressure, diastolic blood pressure, heart rate, and biochemical parameters (serum TP, BUN, CPK, AST, and $\mathrm{LDH}$ ) did not differ among the three groups at any examination points.

Metabolic and hormonal parameters after citric acid and L-carnitine administration are summarized in Table 3. The three groups did not differ with respect to plasma glucose, blood lactate level, serum triglyceride, free fatty acids, ketone bodies, cortisol, plasma ACTH or serum citric acid levels at any examination points. However, before the physical load, the salivary chromogranin A level was lower in the citric acid group than in the placebo group. Also, serum L-carnitine and acyl-carnitine levels were higher in the L-carnitine group than in the placebo group before the physical load, at the end of the physical load, and after the recovery period.

The performance of the three groups during the physical tests is summarized in Table 4. There were no significant differences among the three groups in the maximum speed of rotation in $10 \mathrm{~s}$.

\section{Discussion}

Acute fatigue is a physiological phenomenon that disappears after a certain period of rest. In contrast, however, long-term fatigue sometimes causes irreversible damages, and the function that is useful in reducing acute fatigue is no longer effective.

In order to assess the effect of substances on physical fatigue, it is important to evaluate the subjects' physical performance. In this study, we performed $10 \mathrm{~s}$ maximum speed trials using a cycle ergometer during the fatigueinducing physical tests. However, neither citric acid (2,700 mg/day) nor L-carnitine ( $1,000 \mathrm{mg} /$ day) could improve physical performance during fatigue-inducing workload tests on a cycle ergometer. This negative result may be relevant to the length of the performance tests: $10 \mathrm{~s}$. Support for this comes from the fact that it takes $8 \mathrm{~s}$ for maximum exercise to deplete the ATP pool in muscle cells. Performance 
Table 2. Effects of citric acid and L-carnitine on subjective feeling of fatigue and physiological and biochemical parameters

\begin{tabular}{|c|c|c|c|c|}
\hline & & Before $(0 \mathrm{~h})$ & After (4 h) & Recovery (8 h) \\
\hline \multirow[t]{3}{*}{ VAS for fatigue } & Placebo & $31.0 \pm 19.7$ & $74.6 \pm 13.2$ & $59.0 \pm 20.5$ \\
\hline & Citric acid & $22.2 \pm 15.6$ & $60.6 \pm 13.5^{* *}$ & $50.1 \pm 16.8$ \\
\hline & L-Carnitine & $31.2 \pm 17.0$ & $73.4 \pm 14.1$ & $65.4 \pm 16.3$ \\
\hline \multirow[t]{3}{*}{ Body weight (kg) } & Placebo & $61.5 \pm 7.7$ & $61.0 \pm 7.5$ & $61.8 \pm 7.6$ \\
\hline & Citric acid & $61.3 \pm 8.1$ & $60.9 \pm 8.0$ & $61.6 \pm 8.0$ \\
\hline & L-Carnitine & $61.5 \pm 8.1$ & $61.0 \pm 7.8$ & $61.1 \pm 7.6$ \\
\hline \multirow[t]{3}{*}{ SBP (mmHg) } & Placebo & $118 \pm 13$ & $117 \pm 12$ & $120 \pm 13$ \\
\hline & Citric acid & $113 \pm 9$ & $115 \pm 9$ & $118 \pm 10$ \\
\hline & L-Carnitine & $115 \pm 13$ & $113 \pm 10$ & $115 \pm 14$ \\
\hline \multirow[t]{3}{*}{ DBP (mmHg) } & Placebo & $70 \pm 9$ & $65 \pm 7$ & $70 \pm 9$ \\
\hline & Citric acid & $69 \pm 6$ & $65 \pm 7$ & $69 \pm 6$ \\
\hline & L-Carnitine & $70 \pm 10$ & $64 \pm 6$ & $70 \pm 10$ \\
\hline \multirow[t]{3}{*}{ HR (bpm) } & Placebo & $70 \pm 10$ & $89 \pm 12$ & $85 \pm 10$ \\
\hline & Citric acid & $71 \pm 8$ & $88 \pm 9$ & $84 \pm 8$ \\
\hline & L-Carnitine & $72 \pm 8$ & $89 \pm 11$ & $85 \pm 8$ \\
\hline \multirow[t]{3}{*}{$\mathrm{TP}(\mathrm{g} / \mathrm{dL})$} & Placebo & $7.4 \pm 0.5$ & $7.7 \pm 0.4$ & $7.2 \pm 0.7$ \\
\hline & Citric acid & $7.5 \pm 0.4$ & $7.5 \pm 0.4$ & $7.2 \pm 0.6$ \\
\hline & L-Carnitine & $7.5 \pm 0.4$ & $7.8 \pm 0.3$ & $7.2 \pm 0.4$ \\
\hline \multirow[t]{3}{*}{ BUN (mg/dL) } & Placebo & $12.5 \pm 2.9$ & $12.0 \pm 2.5$ & $12.1 \pm 3.3$ \\
\hline & Citric acid & $12.8 \pm 3.3$ & $12.1 \pm 2.7$ & $12.3 \pm 2.9$ \\
\hline & L-Carnitine & $12.8 \pm 2.9$ & $12.7 \pm 3.2$ & $13.3 \pm 4.2$ \\
\hline \multirow[t]{3}{*}{ CPK (IU/L) } & Placebo & $85 \pm 25$ & $126 \pm 69$ & $178 \pm 183$ \\
\hline & Citric acid & $88 \pm 31$ & $108 \pm 42$ & $141 \pm 91$ \\
\hline & L-Carnitine & $91 \pm 30$ & $112 \pm 40$ & $120 \pm 37$ \\
\hline \multirow[t]{3}{*}{ AST (IU/L) } & Placebo & $18 \pm 5$ & $20 \pm 5$ & $18 \pm 6$ \\
\hline & Citric acid & $18 \pm 3$ & $20 \pm 6$ & $18 \pm 4$ \\
\hline & L-Carnitine & $18 \pm 6$ & $20 \pm 4$ & $19 \pm 4$ \\
\hline \multirow[t]{3}{*}{ LDH (IU/L) } & Placebo & $150 \pm 11$ & $165 \pm 15$ & $156 \pm 14$ \\
\hline & Citric acid & $151 \pm 13$ & $161 \pm 15$ & $153 \pm 18$ \\
\hline & L-Carnitine & $154 \pm 11$ & $171 \pm 14$ & $158 \pm 14$ \\
\hline
\end{tabular}

VAS, visual analogue scale; SBP, systolic blood pressure; DBP, diastolic blood pressure; HR, heart rate; TP, total protein; BUN, blood urea nitrogen; CPK, creatine phosphokinase; AST, aspartate aminotransferase; LDH, lactate dehydrogenase.

Data are presented as mean \pm SD.

${ }^{* *} p<0.01$, significantly different from the corresponding values of the placebo group (paired $t$ test with Bonferroni correction).

tests done for a longer period of time may possibly give different results.

On the other hand, we found that oral administration of citric acid for 8 days improved the subjective feeling of fatigue during fatigue-inducing workload trials on a cycle ergometer. The VAS scores after $4 \mathrm{hr}$ physical load were 60.6 in the citric acid group and 74.6 in the placebo group. The difference of VAS score, 14.0 is so large that almost all people feel the fatigue reduction in daily life. Although these anti-fatigue effects were observed rather chronically, the increase in serum citric acid level appeared to be transient. The serum citric acid levels, when measured only two hours after the final administration of citric acid, did not show any rise in the citric acid group, which is consistent with its previously reported rapid absorption and metabolism [19]. Therefore, it remains to be elucidated how the transient increase in serum citric acid levels can lead to the continuously observed antifatigue effect.

In addition to subjective improvement of the feeling of fatigue, we also observed that citric acid administration for 
Table 3. Effects of citric acid and $\mathrm{L}_{\mathrm{C}}$-Carnitine on metabolic and hormonal parameters

\begin{tabular}{|c|c|c|c|c|}
\hline & & Before $(0 \mathrm{~h})$ & After (4 h) & Recovery ( $8 \mathrm{~h})$ \\
\hline \multirow[t]{3}{*}{ Glucose (mmol/L) } & Placebo & $5.5 \pm 0.4$ & $4.8 \pm 0.4$ & $6.2 \pm 1.2$ \\
\hline & Citric acid & $5.3 \pm 0.6$ & $4.7 \pm 0.4$ & $6.3 \pm 0.9$ \\
\hline & L-Carnitine & $5.4 \pm 0.3$ & $4.8 \pm 0.3$ & $6.1 \pm 0.8$ \\
\hline \multirow[t]{3}{*}{ Lactate $(\mathrm{mmol} / \mathrm{L})$} & Placebo & $0.79 \pm 0.54$ & $0.94 \pm 0.43$ & $0.93 \pm 0.31$ \\
\hline & Citric acid & $0.80 \pm 0.55$ & $0.92 \pm 0.41$ & $0.90 \pm 0.24$ \\
\hline & L-Carnitine & $0.80 \pm 0.42$ & $0.90 \pm 0.28$ & $0.84 \pm 0.20$ \\
\hline \multirow[t]{3}{*}{$\mathrm{TG}(\mathrm{mg} / \mathrm{dL})$} & Placebo & $87 \pm 44$ & $86 \pm 39$ & $59 \pm 28$ \\
\hline & Citric acid & $89 \pm 54$ & $86 \pm 49$ & $62 \pm 41$ \\
\hline & L-Carnitine & $93 \pm 68$ & $93 \pm 57$ & $63 \pm 41$ \\
\hline \multirow[t]{3}{*}{ FFA (mEq/L) } & Placebo & $0.29 \pm 0.15$ & $1.46 \pm 0.45$ & $0.07 \pm 0.08$ \\
\hline & Citric acid & $0.29 \pm 0.14$ & $1.47 \pm 0.53$ & $0.04 \pm 0.03$ \\
\hline & L-Carnitine & $0.26 \pm 0.08$ & $1.48 \pm 0.44$ & $0.04 \pm 0.02$ \\
\hline \multirow[t]{3}{*}{$\mathrm{KB}(\mu \mathrm{mol} / \mathrm{l})$} & Placebo & $38 \pm 25$ & $595 \pm 246$ & $18 \pm 11$ \\
\hline & Citric acid & $51 \pm 46$ & $664 \pm 250$ & $16 \pm 5$ \\
\hline & L-Carnitine & $44 \pm 40$ & $681 \pm 263$ & $18 \pm 6$ \\
\hline \multirow[t]{3}{*}{$\mathrm{AA}(\mu \mathrm{mol} / \mathrm{L})$} & Placebo & $11 \pm 5$ & $118 \pm 55$ & $11 \pm 6$ \\
\hline & Citric acid & $15 \pm 10$ & $134 \pm 57$ & $10 \pm 3$ \\
\hline & L-Carnitine & $13 \pm 7$ & $134 \pm 53$ & $12 \pm 5$ \\
\hline \multirow[t]{3}{*}{ 3-OHBA $(\mu \mathrm{mol} / \mathrm{L})$} & Placebo & $27 \pm 20$ & $477 \pm 195$ & $7 \pm 6$ \\
\hline & Citric acid & $36 \pm 36$ & $530 \pm 196$ & $6 \pm 3$ \\
\hline & L-Carnitine & $31 \pm 34$ & $547 \pm 216$ & $6 \pm 2$ \\
\hline \multirow[t]{3}{*}{ Cortisol (nmol/L) } & Placebo & $533.8 \pm 125.0$ & $373.8 \pm 165.7$ & $365.5 \pm 187.6$ \\
\hline & Citric acid & $481.8 \pm 107.5$ & $385.0 \pm 175.2$ & $314.0 \pm 101.1$ \\
\hline & L-Carnitine & $493.8 \pm 117.2$ & $390.7 \pm 171.8$ & $302.7 \pm 122.3$ \\
\hline \multirow[t]{3}{*}{ ACTH (pmol/L) } & Placebo & $7.7 \pm 4.2$ & $6.2 \pm 2.3$ & $4.9 \pm 2.4$ \\
\hline & Citric acid & $7.4 \pm 4.5$ & $6.8 \pm 3.5$ & $3.6 \pm 2.0$ \\
\hline & L-Carnitine & $6.8 \pm 2.6$ & $7.6 \pm 6.3$ & $3.8 \pm 2.0$ \\
\hline \multirow[t]{3}{*}{ Citric acid $(\mu \mathrm{mol} / \mathrm{L})$} & Placebo & $81.0 \pm 25.6$ & $109.0 \pm 29.2$ & $68.0 \pm 19.4$ \\
\hline & Citric acid & $83.3 \pm 27.4$ & $116.0 \pm 35.1$ & $70.3 \pm 21.3$ \\
\hline & L-Carnitine & $81.0 \pm 21.3$ & $113.3 \pm 26.3$ & $70.0 \pm 19.2$ \\
\hline \multirow[t]{3}{*}{ Total carnitine $(\mu \mathrm{mol} / \mathrm{L})$} & Placebo & $63 \pm 11$ & $65 \pm 12$ & $59 \pm 11$ \\
\hline & Citric acid & $64 \pm 10$ & $64 \pm 11$ & $58 \pm 10$ \\
\hline & L-Carnitine & $78 \pm 10^{* *}$ & $96 \pm 12 * *$ & $80 \pm 11 * *$ \\
\hline \multirow[t]{3}{*}{ L-Carnitine $(\mu \mathrm{mol} / \mathrm{L})$} & Placebo & $54 \pm 10$ & $43 \pm 8$ & $52 \pm 10$ \\
\hline & Citric acid & $54 \pm 9$ & $42 \pm 8$ & $52 \pm 9$ \\
\hline & L-Carnitine & $66 \pm 12^{* *}$ & $61 \pm 11^{* *}$ & $70 \pm 9 * *$ \\
\hline \multirow[t]{3}{*}{ Acyl-carnitine $(\mu \mathrm{mol} / \mathrm{L})$} & Placebo & $9 \pm 2$ & $22 \pm 5$ & $7 \pm 2$ \\
\hline & Citric acid & $10 \pm 4$ & $22 \pm 5$ & $6 \pm 3$ \\
\hline & L-Carnitine & $12 \pm 3^{*}$ & $34 \pm 6^{* *}$ & $10 \pm 4 * *$ \\
\hline \multirow[t]{3}{*}{ CGA/TP (pmol/mg) } & Placebo & $1.858 \pm 0.629$ & $1.324 \pm 0.997$ & $0.969 \pm 0.630$ \\
\hline & Citric acid & $1.192 \pm 0.491^{* *}$ & $1.017 \pm 1.127$ & $0.920 \pm 0.631$ \\
\hline & L-Carnitine & $1.480 \pm 0.456$ & $1.127 \pm 0.665$ & $0.978 \pm 0.487$ \\
\hline
\end{tabular}

TG, triglyceride; FFA, free fatty acids; KB, ketone bodies; AA, acetoacetic acid; 3-OHBA, 3hydroxybutyric acid; ACTH, adrenocorticotropic hormone; CGA/TP, chromogranin A/total protein ratio.

Data are presented as mean \pm SD.

${ }^{* *} p<0.01,{ }^{*} p<0.05$, significantly different from the corresponding values of the placebo group (paired $t$-test with Bonferroni correction). 
Table 4. Effects of citric acid and L-carnitine on subjects' performance during physical load

\begin{tabular}{llccc}
\hline & & at $30-$ min trial & at 210 -min trial & delta \\
\hline Maximum & Placebo & $82.8 \pm 28.3$ & $76.4 \pm 27.3$ & $-6.4 \pm 9.8$ \\
Speed (rpm) & Citric acid & $79.2 \pm 28.7$ & $76.7 \pm 28.4$ & $-2.4 \pm 6.6$ \\
& L-Carnitine & $80.6 \pm 26.5$ & $77.4 \pm 28.5$ & $-3.2 \pm 7.2$ \\
\hline
\end{tabular}

During the physical tests, subjects were asked to perform $10 \mathrm{~s}$ maximum speed trial using a cycle ergometer at $30 \mathrm{~min}(30-\mathrm{min}$ trial) after the start and $30 \mathrm{~min}$ before the end of the test (210-min trial).

Data are presented as mean $\pm \mathrm{SD}$.

one week reduces the pre-physical load level of salivary chromogranin A. Chromogranin A was first identified as the soluble protein discovered in adrenal chromaffin granules $[20]$ and was later found to exist in various endocrine organs and sympathetic neurons [21]. Chromogranin A is released into the extra-cellular matrix with catecolamines and released into saliva by physiological stress. Our present results may indicate that citric acid reduces the physiological stress before the physical exertion and attenuates the subjective fatigue feeling that our subjects reported on the visual analogue scale.

The administration of another substance, L-carnitine, for 8 days failed to cause any significant differences at all time points for all physiological or biochemical markers investigated except for serum L-carnitine and acylcarnitine levels. However, it is possible that the test schedule or dose used in the present study may not have been suitable for investigating the anti-fatigue effects of $\mathrm{L}$-carnitine. Although there was a small rise in the serum concentration of $\mathrm{L}$ carnitine and acylcarnitine in the $\mathrm{L}$-carnitine group, a longer administration may have induced a further rise of carnitine in serum and thereby exert a stringer effect. Indeed, it is known that there seems to be carnitine pool in a human body and therefore it usually takes more than a month for serum carnitine levels to reach the plateau. Moreover, the previous studies were performed at $1-3 \mathrm{~g} /$ day administration for $1-8$ weeks $[13,14]$, so further study involving higher dose and longer period of carnitine administration may be required.

We demonstrated that oral citric acid improved the subjective fatigue feeling during a fatigue-inducing workload test and reduced physiological stress. To avoid long-term fatigue, it is important to develop effective strategies that attenuate fatigue; citric acid use may prevent the unfavorable consequences of accumulated physical fatigue.

\section{Acknowledgments}

We thank Dr. Kathy Meister for editorial help with the manuscript.

\section{References}

[1] Ream, E. and Richardson, A.: Fatigue in patients with cancer and chronic obstructive airways disease: a phenomenological enquiry. Int. J. Nurs. Stud., 34, 44-53, 1997.

[2] Ream, E. and Richardson, A.: Fatigue: a concept analysis. Int. J. Nurs. Stud., 33, 519-529, 1996.

[3] Grandjean, E.P.: Fatigue. Am. Ind. Hyg. Assoc. J., 31, 401411,1970

[4] Aoi, W., Naito, Y., and Yoshikawa, T.: Exercise and functional foods. Nutr. J., 5, 15, 2006.

[5] Chaudhuri, A. and Behan, P.O.: Fatigue in neurological disorders. Lancet, 363, 978-988, 2004.

[6] Sahlin, K., Tonkonogi, M., and Söderlund, K.: Energy supply and muscle fatigue in humans. Acta. Physiol. Scand., 162, 261-266, 1998.

[7] Baldwin, J.E. and Krebs, H.A.: The evolution of metabolic cycles. Nature, 291, 381-382, 1981.

[8] Sahlin, K., Katz, A., and Broberg, S.: Tricarboxylic acid cycle intermediates in human muscle during prolonged exercise. Am. J. Physiol., 259, C834-841,1990.

[9] Cheema-Dhadli, S., Halperin M.L., and Leznoff, C.C.: Inhibition of enzymes which interact with citrate (-)hydroxycitrate and 1,2,3-tricarboxybenzene. Eur. J. Biochem., 38, 98-102, 1973.

[10] Kiyose, C., Ogino, S., Kubo, K., Takeuchi, M., and Saito, M.: Relationship between Garcinia cambogia-induced impairment of spermatogenesis and meiosis-activating sterol production in rat testis. J. Clin. Biochem. Nutr., 38, 180-187, 2006.

[11] Kiyose, C., Kubo, K., and Saito, M.: Effect of Garcinia cambogia administration on female reproductive organs in rats. J. Clin. Biochem. Nutr., 38, 188-194, 2006.

[12] Eaton, S., Bartlett, K., and Pourfarzam, M.: Mammalian mitochondrial $\beta$-oxidation. Biochem. J., 320, 345-357, 1996.

[13] Pliopys, A.V. and Pliopys, S.: Serum levels of carnitine in chronic fatigue syndrome: clinical correlates. Neuropsychobiology, 32, 132-138, 1995.

[14] Pliopys, A.V. and Pliopys, S.: Amantadine and L-carnitine treatment of chronic fatigue syndrome. Neuropsychobiology, 35, 16-23, 1997.

[15] Koikawa, N., Nakamura, A., Toyoshima, H., Mieda, H., Nagaoka, I., Yamaguchi, M., and Sawaki, K.: Effect of lemon fruit juice intake on the hemorheologic changes and blood biochemistry in long distance runners. Researc, Quarterly for Athletics, 59, 20-26, 2004. 
[16] Ataka, S., Tanaka, M., Nozaki, S., Mizuma, H., Mizuno, K., Tahara, T., Sugino, T., Shirai, T., Kajimoto, Y., Kuratsune, H., Kajimoto, O., and Watanabe, Y.: Effects of Applephenon and ascorbic acid on physical fatigue. Nutrition, 23, 419423, 2007.

[17] Maxwell, C.: Sensitivity and accuracy of the visual analogue scale: a psycho-physical classroom experiment. Br. J. Clon. Pharmacol., 6, 15-24, 1978.

[18] Leung, A.W., Chan, C.C., Lee, A.H., and Lam, K.W.: Visual analogue scale correlates of musculoskeletal fatigue. Percept. Mot. Skills, 99, 235-246, 2004.
[19] Yasukawa, S., Uehara, M., Yamauchi, T., Morimoto, S., Ebisuno, S., and Ohkawa, T.: Citrate as an inhibitor of stone formation with reference to intestinal citrate absorption and the influence of citrate on intestinal calcium absorption. Hinyokika Kiyo, 37, 1103-1106, 1991.

[20] Helle, H.B.: Some chemical and physical properties of the soluble protein fraction of bovine adrenal chromaffin granules. Mol. Pharmacol., 2, 298-310, 1966.

[21] Winkler, H. and Fischer-Colibrie, R.: The chromogranins A and B: the first 25 years and future perspectives. Neuroscience, 49, 497-528, 1992. 